\title{
Microcirculatory mechanisms in postnatal hypotension affecting premature infants
}

\author{
Alexandra Schwepcke', Florian D. Weber' ', Zuzana Mormanova' ', Bystrik Cepissak and Orsolya Genzel-Boroviczény'
}

BACKGROUND: Hypotension remains a common complication in preterm infants and is associated with high neonatal morbidity and mortality. The underlying mechanisms are still not fully understood. We studied the microcirculation in extremely low birth weight infants to understand the relationship between blood pressure and skin perfusion.

METHODS: In 21 patients (gestational age <30wk, birth weight $<1,225 \mathrm{~g}$ ), functional vessel density (FVD) and diameter distribution were obtained prospectively by side stream darkfield imaging at the right arm in the first $48 \mathrm{~h}$ after birth. Infants with blood pressure below gestational age and receiving catecholamines were defined as hypotensive as compared with the remaining normotensive control group.

RESULTS: In the first $6 \mathrm{~h}$ after birth, FVD was significantly higher in the hypotensive group than in the control group. After $12 \mathrm{~h}$, there were no significant differences in either blood pressure or FVD between the two groups. FVD did not change significantly during the observation period in either group.

CONCLUSION: Hypotensive infants have a higher FVD, possibly due to loss of microvascular tone leading to vasodilation and flow redistribution. However, the link between blood pressure and perfusion remains unclear, and no definitive correlation could be found.

$S_{\text {is }}$ stemic hypotension is common in preterm infants and is associated with high neonatal morbidity and mortality. Failing to treat hypotension can lead to severe shock, characterized by acute circulatory failure, inadequate tissue oxygenation, and organ perfusion, resulting in metabolic acidosis (1-3). Hypotension is frequently first treated by repeated boluses of isotonic saline to fill the vasculature, followed by treatment with pressors (dopamine, epinephrine, norepinephrine) to tighten the vasculature, and inotrope agents (dobutamine) and/or hydrocortisone to compensate for the immature vasculature (4-7).

There is an ongoing debate regarding which is the lowest acceptable normal blood pressure $(2,3,8-11)$. There is general agreement but no real scientific evidence to accept the equivalent of the gestational age as the lower limit for the mean arterial blood pressure (MAP) during the first postnatal days (12). Conclusive data are lacking to determine which blood pressure levels actually harm extremely low birth weight infants. Therefore, treating low blood pressure values without evidence of metabolic acidosis-and therefore clear signs of inadequate tissue oxygenation-should be questioned. Because global hemodynamic parameters, such as blood pressure and heart rate, do not reflect adequate tissue oxygenation, it becomes essential to study the microcirculation (13).

Side dark field (SDF) imaging is a relatively new technique to visualize the microcirculation at the bedside $(14,15)$. The technique consists of a handheld microscope with light-emitting diodes. The lens can be placed on the arm of the neonate and thus the microcirculation of the skin can be observed. The light (wavelength within the absorption spectrum of hemoglobin) is absorbed by erythrocytes but reflected by the tissue. Thus an in vivo image of perfused vessels can be obtained and subsequently analyzed by measuring the length of capillaries per image area and the diameter distribution of the vessels $(16,17)$. Therefore, these measurements of the microcirculation can be compared at different time points and before and after treatment. This might add more information about the perfusion in neonates in health and disease.

The objective of this prospective study was to analyze microcirculatory mechanisms in postnatal hypotension in preterm infants in the first $48 \mathrm{~h}$ of life.

\section{RESULTS}

The data of 21 of 34 prospectively enrolled preterm infants could be analyzed, and 7 neonates had to be excluded due to infection. The data points of six neonates (one in the hypotensive group, five in the control group) were excluded retrospectively because they had a gestational age $>30 \mathrm{wk}$. In each of the groups, one infant could not be measured in time for the first data point; two values at $48 \mathrm{~h}$ of life in the hypotensive group and two values in the control group are missing due to technical problems.

As can be seen in Table 1, the clinical data of 10 hypotensive and 11 normotensive neonates did not differ significantly, except for sex, with more males in the hypotensive group. Nine of the 10 hypotensive neonates had an umbilical arterial line placed as compared with only 3 of the 11 controls.

A.S. and F.D.W. contributed equally to this work and share first authorship. These data are part of the thesis of B.C.

'Division of Neonatology, Dr. von Hauner Children's Hospital, University of Munich, Munich, Germany. Correspondence: Orsolya Genzel-Boroviczény

(genzel@med.uni-muenchen.de) 
At $6 \mathrm{~h}$ after birth, MAP was significantly lower in the hypotensive than in the control group (Table 2), with no significant difference at 12,24 , and $48 \mathrm{~h}$. None of the other clinical variables, such as hematocrit, heart rate, or body temperature differed between the two groups. Dobutamine was started in the hypotensive group before $6 \mathrm{~h}$ of age in eight infants and between 6 and $12 \mathrm{~h}$ in two infants. At $12 \mathrm{~h}$ of life, 9 of the 10 hypotensive infants received dobutamine $(2-10 \mu \mathrm{g} / \mathrm{kg} / \mathrm{min})$. In two infants, dopamine was added to the dobutamine for persistent hypotension $(2-12 \mu \mathrm{g} / \mathrm{kg} / \mathrm{min})$. At $24 \mathrm{~h}$ only five infants required the continuation of dobutamine treatment $(1-3.5 \mu \mathrm{g} / \mathrm{kg} / \mathrm{min})$, and one infant received only dopamine $(5 \mu \mathrm{g} / \mathrm{kg} / \mathrm{min})$. At $48 \mathrm{~h}$, in nine of the 10 hypotensive infants, catecholamines were stopped.

In the hypotensive group and in the control group, functional vessel density (FVD) did not change during the first $48 \mathrm{~h}$ of life (Table 3). At $6 \mathrm{~h}$ after birth, FVD was significantly higher in infants treated with catecholamines than that in the control group infants (Figure 1 and Table 3), whereas MAP was significantly lower. At all other time points, FVD and blood pressure did not differ between the groups. Diameter distribution did not change during the first $48 \mathrm{~h}$ of life and did not differ between both groups (Table 4).

\section{DISCUSSION}

We demonstrated that hypotensive preterm infants requiring catecholamine treatment have a significantly lower MAP and a higher FVD at $6 \mathrm{~h}$ of life in comparison with normotensive infants. During successful treatment, leading to similar blood

Table 1. Clinical data

\begin{tabular}{lcc}
\hline & Hypotensive & Control \\
\hline Birth weight $(\mathrm{g})$ & $815(636-994)$ & $883(725-1,041)$ \\
Gestational age $(\mathrm{wk})$ & $26.1(24.8-27.5)$ & $27.1(25.9-28.3)$ \\
Apgar score & & \\
$\quad$ Minute 1 & $6.1(3.9-8.3)$ & $6.5(4.6-8.5)$ \\
$\quad$ Minute 5 & $7.9(6.5-9.4)$ & $8.3(6.7-9.8)$ \\
$\quad$ Minute 10 & $8.7(7.6-9.8)$ & $8.8(7.7-9.9)$ \\
Tracheal intubation (\%) & 90 & 45 \\
Male (\%) & $87^{*}$ & $36^{*}$ \\
hsPDA during hospital course (\%) & 50 & 81 \\
Umbilical arterial catheter & $90^{*}$ & $27^{*}$ \\
\hline
\end{tabular}

Values are given as mean $(95 \% \mathrm{Cl})$ or as percentages.

$\mathrm{Cl}$, confidence interval; $\mathrm{hsPDA}$, hemodynamically significant patent ductus arteriosus. ${ }^{*} P<0.05$ unpaired $t$-test.

Table 2. Mean arterial blood pressure at the four time points (in $\mathrm{mmHg}$ )

\begin{tabular}{lcccc}
\hline Group & Hour 6 & Hour 12 & Hour 24 & Hour 48 \\
\hline Hypotensive & $29.7(25-34)^{*}$ & $31.7(28-35)$ & $32.1(29-35)$ & $32.9(28-38)$ \\
Control & $34.9(31-39)^{*}$ & $36.1(33-39)$ & $34.8(30-40)$ & $38.1(35-42)$ \\
\hline
\end{tabular}

Values are given as mean $(95 \% \mathrm{Cl})$.

$\mathrm{Cl}$, confidence interval.

* $P<0.05$, hypotensive group vs. control (Mann-Whitney test). pressure to that of the normotensive infants, FVD did not differ at 12,24 , or $48 \mathrm{~h}$ of life.

Contributing factors to low blood pressure in neonateswithout evidence of shock-include abnormal peripheral vasoregulation due to immaturity of receptors and systems that regulate blood pressure, perinatal asphyxia, hemodynamically significant patent ductus arteriosus, infection, and relative adrenal insufficiency $(3,18,19)$. Because we excluded asphyxia and infection in our study group and there were no differences in the prevalence of patent ductus arteriosus, the low blood pressure in our hypotensive group can possibly be explained by an abnormal peripheral vasoregulation and adrenal insufficiency. SDF imaging provides the technique to visualize abnormal peripheral vasoregulation by using a microscope at the bedside. In our study, we saw a higher FVD at $6 \mathrm{~h}$ of life in the hypotensive group, relatively soon after the start of antihypotension treatment. At this time point, blood pressure in the hypotensive group was significantly lower. Therefore, the increased FVD at $6 \mathrm{~h}$ of life could possibly be due to a loss in microvascular tone and resulting flow redistribution. This effect could be exacerbated by the use of dobutamine.

Because the vasoactive treatment has an effect on peripheral perfusion, this might also be an additional explanation for our findings. Treatment in the hypotensive group started with dobutamine, a relatively cardioselective amine with $\alpha$ and $\beta$ receptor-mediated inotropic effects. In its most effective range $(2-15 \mu \mathrm{g} / \mathrm{kg} / \mathrm{min})$, hypotension is treated by significantly increasing the left-ventricular output $(10,20-22)$. On the other

Table 3. Functional vessel density (in $1 / \mathrm{cm}$ )

\begin{tabular}{lcccc}
\hline & Hour 6 & Hour 12 & Hour 24 & Hour 48 \\
\hline Hypotensive & 235 & 230 & 219 & 224 \\
& $(222-249)^{*}$ & $(216-243)$ & $(205-233)$ & $(210-239)$ \\
Control & 211 & 215 & 219 & 229 \\
& $(197-225)^{*}$ & $(200-229)$ & $(205-232)$ & $(216-240)$ \\
\hline
\end{tabular}

Values are given as mean $(95 \% \mathrm{Cl})$

$\mathrm{Cl}$, confidence interval.

${ }^{*} P<0.05$, hypotensive group vs. control group (unpaired $t$-test).

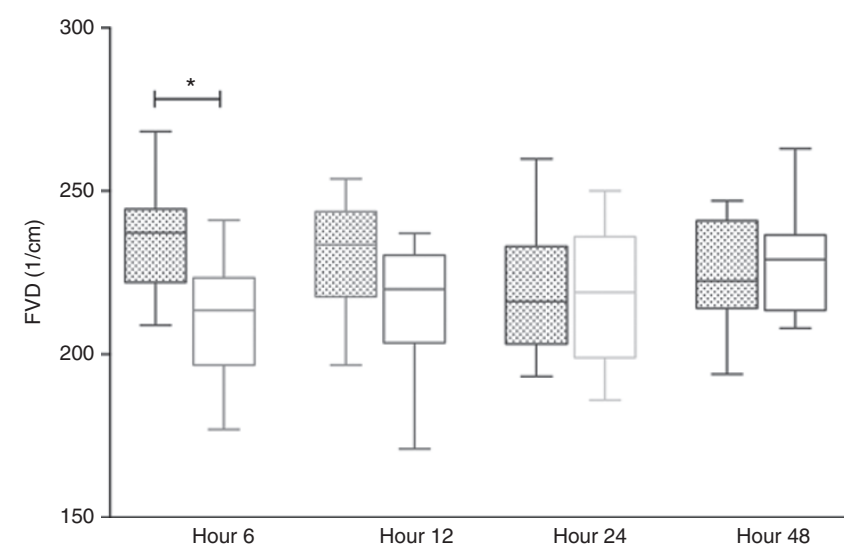

Figure 1. Functional vessel density (FVD) for the hypotensive (shaded) and control (unshaded) groups at $6,12,24$, and $48 \mathrm{~h}$ of life. FVD is significantly $\left(^{*}\right)$ different between the two groups at $6 \mathrm{~h}$ of life. 


\section{Articles | Schwepcket al.}

Table 4. Vessel diameter distribution (in \%)

\begin{tabular}{|c|c|c|c|c|c|}
\hline & & Hour 6 & Hour 12 & Hour 24 & Hour 48 \\
\hline \multirow[t]{2}{*}{ Small vessels $(<10 \mu \mathrm{m})$} & Hypotensive & $36(29-43)$ & $34(25-42)$ & $30(20-40)$ & $37(29-45)$ \\
\hline & Control & $35(26-42)$ & $32(27-37)$ & $34(27-41)$ & $40(34-46)$ \\
\hline Medium vessels $(10-20 \mu \mathrm{m})$ & Control & $56(52-60)$ & $61(58-65)$ & $59(54-63)$ & $53(50-57)$ \\
\hline Large vessels $(>20 \mu \mathrm{m})$ & Hypotensive & $8(5-11)$ & $8(5-10)$ & $11(7-15)$ & $8(5-10)$ \\
\hline
\end{tabular}

Values are given as mean $(95 \% \mathrm{Cl})$.

$\mathrm{Cl}$, confidence interval.

hand, dobutamine is associated with a variable decrease in peripheral vascular resistance, mediated through $\beta 2$ peripheral adrenergic and dopaminergic vascular receptors, resulting in peripheral vasodilatation. This could explain an increased FVD due to dobutamine treatment (23-25).

However, some of our children also received dopamine. Dopamine has very contrary effects on peripheral perfusion; it increases blood pressure by influencing preload, myocardial contractility, and afterload. Its most important effect results from peripheral vasoconstriction, an effect derived from stimulating peripheral $\alpha 1 / \alpha 2$ adrenergic and dopaminergic receptors. This effect could be further intensified by dobutamine (23-25). Therefore, one would expect a reduced FVD in the skin. In our opinion, our results could derive from a mixture of different effects: on one hand, an abnormal vasoregulation and vasodilatatory mechanism could be the main cause for low blood pressure in the hypotensive group and thus explain a higher FVD in the first $12 \mathrm{~h}$ of life (26). These could be intensified by dobutamine, which was the main treatment for arterial hypotension in our hypotensive group. We had only three patients who were treated with very low-dose dopamine in addition to dobutamine, so its vasoconstrictive effects might not be visible in our observational study.

Peripheral oxygenation management is essential for the outcome of the child. However, central blood pressure is only a poor indicator for oxygen delivery to the demanding tissues $(27,28)$. Therefore, measuring microcirculatory blood flow could be regarded as an important addition to the usual macrocirculatory parameters. Microcirculatory parameters have been shown to be able to visualize dysfunctional microcirculation in septic shock in children, effects of inhaled nitric oxide in children with hypoxemic respiratory failure, and in children receiving extracorporeal membrane oxygenation (29-31).

Possibly, microcirculatory parameters could help to assess the effect of hypotension on the microcirculation on an individual level and might help to derive specific, individual treatment decisions. We concentrated on the skin of preterm infants. At the moment, it is not possible to assess the microcirculation in central organs (brain, lungs, and intestine).

The predominance of boys in the hypotensive group and of girls in the control group is not surprising but is of great interest. We know that male preterm infants have a higher risk for mortality and morbidity (32). Preterm females have significantly higher catecholamine levels than males; this might be an important reason for a higher prevalence of males in our hypotensive group (33). Our results in regard to gender are in agreement with data from Stark et al. (34). Using laser Doppler flowmetry, they found higher baseline flow during the first $24 \mathrm{~h}$ in extremely preterm boys with gestational age $24-28 \mathrm{wk}$, with a significant relationship to the vasodilatory effect of acetylcholine. There are many limitations to our study. The microcirculation in preterm infants is affected by many factors, such as hemoglobin level, incubator temperature, and maturity. Due to the retrospective exclusion of neonates of $>30$ wk of gestation, most clinical variables did not differ between our two groups.

The hypotensive group had a higher percentage of infants in whom arterial blood pressure was measured by an umbilical arterial catheter. Because blood pressure values are lower when obtained from an umbilical arterial catheter vs. cuff, this could be an important bias in our data. However, because the umbilical arterial catheter was not removed before the 48th $\mathrm{h}$ of life in our patients and we did not observe a significant difference in MAP at the later time points, it is unlikely that the difference in blood pressure at the 6 th $\mathrm{h}$ of life is solely due to this.

Finally, because of the very time-consuming methods and analysis, as well as a strict time frame, the number of our patients is low and the statistical power is limited.

\section{Conclusion}

In conclusion, our results demonstrate significant differences in the microcirculation between hypotensive and normotensive premature infants. At $6 \mathrm{~h}$ after birth, FVD is higher in the hypotensive group, whereas blood pressure is significantly lower than that in the control group. There are no differences in blood pressure and FVD after $12 \mathrm{~h}$ of age.

The increased FVD could possibly be due to a loss in microvascular tone and flow distribution causing the hypotension. This effect could further be intensified by dobutamine.

However, the link between blood pressure and perfusion remains unclear, and no definitive correlation could be found. SDF imaging could nevertheless be an excellent method to study the effects of arterial hypotension on microcirculation in vivo and help to assess potential benefits of antihypotensive therapy.

\section{METHODS}

Our single-center, prospective, observational study was conducted between October 2006 and October 2008 at the neonatal intensive care unit of the Children's University Hospital Munich, Munich, Germany. Preterm inborn infants with gestational ages $<32 \mathrm{wk}$ and a birth weight $<1,500 \mathrm{~g}$ admitted to the neonatal intensive care unit 


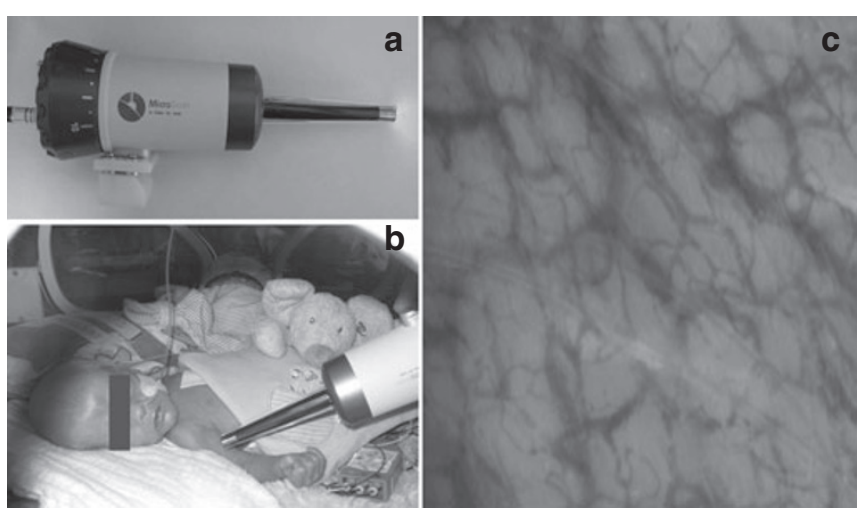

Figure 2. Measurement of the microcirculation. (a) Presentation of the side dark field (SDF) imaging device, (b) a measurement on a preterm neonate, and (c) the resulting photograph.

were consecutively included after written and oral parental consent. Neonates who received pressor or positive inotrope treatment for arterial hypotension within $12 \mathrm{~h}$ after birth were assigned to the hypotensive group, and infants needing no support to maintain their arterial blood pressure in the physiologic range were assigned to the control group. Exclusion criteria were signs of infection-defined as a C-reactive protein level $>1.0 \mathrm{mg} / \mathrm{dl}$ - or congenital malformations. The institutional review board of the Medical Faculty of the Ludwig Maximilians University approved the study protocol and the consent forms.

Because only one neonate with a gestational age above $30 \mathrm{wk}$ received treatment for hypotension, the data of infants with a gestational age above $30 \mathrm{wk}$ were excluded to avoid bias of the results.

Infants were monitored according to standard procedure of the intensive care nursery, and treatment was independent from the study and at the discretion of the attending neonatologist. Blood pressure measurements were obtained continuously if an umbilical arterial line was in place; otherwise, measurements were obtained every 5-15 min with an oscillatory device (Dinamap Critikon Vital Data Monitor; Critikon, Norderstedt, Germany) until the infant's MAP was constantly in the physiologic range and thereafter every $2 \mathrm{~h}$. Hypotension was defined as MAP below the equivalent of the gestational age and was treated with a volume bolus of $10-20 \mathrm{ml} / \mathrm{kg}$ body weight over 30-60 min. If this did not result in normotension, catecholamine treatment was started, usually with dobutamine (starting dose $5 \mu \mathrm{g} / \mathrm{kg} /$ $\mathrm{min}$ ); this was increased, if necessary, to $10 \mu \mathrm{g} / \mathrm{kg} / \mathrm{min}$. If hypotension persisted, dopamine infusion was added (starting with $5 \mu \mathrm{g} / \mathrm{kg} / \mathrm{min}$ ).

As described in the introduction, SDF imaging (Microvision Medical, Wallingford, PA) is a noninvasive video microscopic method to visualize microcirculation and has been previously used for assessing the microcirculation in very premature infants (35). Green light $(530 \mathrm{~nm})$ is emitted by light-emitting diodes and absorbed by the hemoglobin in erythrocytes but scattered by other structures of the tissue. Therefore, a noninvasive, functional image is obtained. In Figure $2 \mathrm{a}-\mathrm{c}$, a picture of the handheld video microscope, a measurement on a preterm neonate, and the resulting microcirculatory measurements are shown.

In this study, we used the video microscope MicroScan with $\times 5$ magnification. SDF images of $10 \mathrm{~s}$ were obtained on three different spots of the right inner upper arm (preductal arm). As we have shown previously, the upper region of the arm provides a good image quality and is easy to access (36-38).

Microcirculatory measurements were performed at four time points, specifically at $6,12,24$, and $48 \mathrm{~h}$ of life. Measurements and analyses were performed by two investigators. Images underwent blinded off-line analysis with Microvision analysis software (Microscan BV, Amsterdam, The Netherlands). This software semiautomatically detects vessels on the screen and allows manual correction for artifacts such as lanugo hair. Accordingly, microcirculatory parameters such as FVD and the distribution of vessel diameters are calculated.
FVD represents the total vessel length in centimeters per image area in square centimeters. The distribution of vessels in small $(<10 \mu \mathrm{m})$, medium $(10-20 \mu \mathrm{m})$, and large vessels $(>20 \mu \mathrm{m})$ is calculated according to the percentage of total vessel length. Statistical analysis was performed with GraphPrism 6.0 (GraphPad Software, La Jolla, CA). Data are presented as mean values with $95 \%$ confidence intervals. For each time point, three video scans were analyzed, and the mean value of a variable was used for statistical analysis. Intergroup comparison was performed with the unpaired $t$-test after having passed normality test for parametric data. A $P$ value of $<0.05$ was considered to be significant. The two investigators analyzing the scans trained together on 10 examples. Then, 10 new video scans were tested for interindividual variance, which was not significantly different.

\section{STATEMENT OF FINANCIAL SUPPORT}

No financial assistance was received to support this study.

Disclosure: The authors declare no conflict of interest.

\section{REFERENCES}

1. Efird MM, Heerens AT, Gordon PV, Bose CL, Young DA. A randomizedcontrolled trial of prophylactic hydrocortisone supplementation for the prevention of hypotension in extremely low birth weight infants. J Perinatol 2005;25:119-24.

2. Fanaroff AA, Fanaroff JM. Short- and long-term consequences of hypotension in ELBW infants. Semin Perinatol 2006;30:151-5.

3. Seri I. Circulatory support of the sick preterm infant. Semin Neonatol 2001;6:85-95.

4. Barrington KJ. Hypotension and shock in the preterm infant. Semin Fetal Neonatal Med 2008;13:16-23.

5. Limperopoulos C, Bassan H, Kalish LA, et al. Current definitions of hypotension do not predict abnormal cranial ultrasound findings in preterm infants. Pediatrics 2007;120:966-77.

6. Logan JW, O'Shea TM, Allred EN, et al.; ELGAN Study Investigators. Early postnatal hypotension and developmental delay at 24 months of age among extremely low gestational age newborns. Arch Dis Child Fetal Neonatal Ed 2011;96:F321-8.

7. Schmaltz C. Hypotension and shock in the preterm neonate. Adv Neonatal Care 2009;9:156-62.

8. Barrington KJ. Low blood pressure in extremely preterm infants: does treatment affect outcome? Arch Dis Child Fetal Neonatal Ed 2011; 96:F316-7.

9. Batton BJ, Li L, Newman NS, et al.; Eunice Kennedy Shriver National Institute of Child Health and Human Development Neonatal Research Network. Feasibility study of early blood pressure management in extremely preterm infants. J Pediatr 2012;161:65-9.e1.

10. Seri I, Noori S. Diagnosis and treatment of neonatal hypotension outside the transitional period. Early Hum Dev 2005;81:405-11.

11. Vain NE, Barrington KJ. Feasibility of evaluating treatment of early hypotension in extremely low birth weight infants. J Pediatr 2012;161:4-7.

12. Nuntnarumit P, Yang W, Bada-Ellzey HS. Blood pressure measurements in the newborn. Clin Perinatol 1999;26:981-96, x.

13. Trzeciak S, Rivers EP. Clinical manifestations of disordered microcirculatory perfusion in severe sepsis. Crit Care 2005;9:Suppl 4:S20-6.

14. Goedhart PT, Khalilzada M, Bezemer R, Merza J, Ince C. Sidestream Dark Field (SDF) imaging: a novel stroboscopic LED ring-based imaging modality for clinical assessment of the microcirculation. Opt Express 2007;15:15101-14.

15. Groner W, Winkelman JW, Harris AG, et al. Orthogonal polarization spectral imaging: a new method for study of the microcirculation. Nat Med 1999;5:1209-12.

16. Boerma EC, Mathura KR, van der Voort PH, Spronk PE, Ince C. Quantifying bedside-derived imaging of microcirculatory abnormalities in septic patients: a prospective validation study. Crit Care 2005;9:R601-6.

17. De Backer D, Hollenberg S, Boerma C, et al. How to evaluate the microcirculation: report of a round table conference. Crit Care 2007;11:R101.

18. Kluckow M. Low systemic blood flow and pathophysiology of the preterm transitional circulation. Early Hum Dev 2005;81:429-37. 
19. Sarkar S, Dechert R, Schumacher RE, Donn SM. Is refractory hypotension in preterm infants a manifestation of early ductal shunting? J Perinatol 2007:27:353-8.

20. Sassano-Higgins S, Friedlich P, Seri I. A meta-analysis of dopamine use in hypotensive preterm infants: blood pressure and cerebral hemodynamics. J Perinatol 2011;31:647-55.

21. Seri I. Management of hypotension and low systemic blood flow in the very low birth weight neonate during the first postnatal week. J Perinatol 2006;26:Suppl 1:S8-13; discussion S22-3.

22. Subhedar NV, Shaw NJ. Dopamine versus dobutamine for hypotensive preterm infants. Cochrane Database Syst Rev 2003:CD001242.

23. Evans JR, Lou Short B, Van Meurs K, Cheryl Sachs H. Cardiovascular support in preterm infants. Clin Ther 2006;28:1366-84.

24. Rozé JC, Tohier C, Maingueneau C, Lefèvre M, Mouzard A. Response to dobutamine and dopamine in the hypotensive very preterm infant. Arch Dis Child 1993;69(1 Spec No):59-63.

25. Ruffolo RR Jr. The pharmacology of dobutamine. Am J Med Sci 1987;294:244-8.

26. Noori S, Stavroudis TA, Seri I. Systemic and cerebral hemodynamics during the transitional period after premature birth. Clin Perinatol 2009;36:723-36, v.

27. Weindling AM. Peripheral oxygenation and management in the perinatal period. Semin Fetal Neonatal Med 2010;15:208-15.

28. Weindling M, Paize F. Peripheral haemodynamics in newborns: best practice guidelines. Early Hum Dev 2010;86:159-65.

29. Top AP, Ince C, de Meij N, van Dijk M, Tibboel D. Persistent low microcirculatory vessel density in nonsurvivors of sepsis in pediatric intensive care. Crit Care Med 2011;39:8-13.
30. Top AP, Ince C, Schouwenberg PH, Tibboel D. Inhaled nitric oxide improves systemic microcirculation in infants with hypoxemic respiratory failure. Pediatr Crit Care Med 2011;12:e271-4.

31. Top AP, Ince C, van Dijk M, Tibboel D. Changes in buccal microcirculation following extracorporeal membrane oxygenation in term neonates with severe respiratory failure. Crit Care Med 2009;37: 1121-4.

32. Stevenson DK, Verter J, Fanaroff AA, et al. Sex differences in outcomes of very low birth weight infants: the newborn male disadvantage. Arch Dis Child Fetal Neonatal Ed 2000;83:F182-5.

33. Ingemarsson I. Gender aspects of preterm birth. BJOG 2003;110:Suppl 20:34-8.

34. Stark MJ, Clifton VL, Wright IM. Sex-specific differences in peripheral microvascular blood flow in preterm infants. Pediatr Res 2008;63: 415-9.

35. Hiedl S, Schwepcke A, Weber F, Genzel-Boroviczeny O. Microcirculation in preterm infants: profound effects of patent ductus arteriosus. J Pediatr 2010;156:191-6.

36. Genzel-Boroviczény O, Christ F, Glas V. Blood transfusion increases functional capillary density in the skin of anemic preterm infants. Pediatr Res 2004;56:751-5.

37. Genzel-Boroviczény O, Strötgen J, Harris AG, Messmer K, Christ F. Orthogonal polarization spectral imaging (OPS): a novel method to measure the microcirculation in term and preterm infants transcutaneously. Pediatr Res 2002;51:386-91.

38. Kroth J, Weidlich K, Hiedl S, Nussbaum C, Christ F, Genzel-boroviczény O. Functional vessel density in the first month of life in preterm neonates. Pediatr Res 2008;64:567-71. 